\title{
Los principios y su evolución en el derecho mercantil
}

Yina Constanza Pérez ${ }^{*}$

* Magíster en Derecho Administrativo. Profesora, Universidad de la Amazonia, Florencia, Caquetá.

Correo electrónico: yinacp@yahoo.es

Recibido: 18 de marzo del 2017

Aprobado: 23 de abril del 2017

Cómo citar este artículo: Yina Constanza Pérez. Los principios y su evolución en el derecho mercantil. DIxI 26. Mayo 2017.

Pág. 119. doi: http://dx.doi.org/10.16925/ di.v19i26.1955

\section{Resumen}

Propósito: este ensayo está orientado a mostrar cómo el derecho mercantil, en cuanto es un comportamiento del hombre en sociedad, no es ajeno a la principialística. Descripción: el hecho de que esta rama de lo jurídico sea relativamente nueva en lo que se refiere a su codificación, evidencia que su génesis es tan antigua como el hombre. Por tanto, este trabajo evidencia la forma en que los principios generales del derecho han permeado a esta especialidad. Punto de vista: la investigación se ocupa de la siguiente cuestión jurídica: ¿de qué manera los principios generales del derecho han permeado el derecho mercantil y cuál ha sido su evolución? Se desarrolla con base en la metodología propuesta en Tomás Austin, y en Frida Gisela Ortiz-Uribe y María del Pilar García. El fundamento teórico es el dado por Hernán Valencia-Restrepo, Norberto Bobbio, Ronald Dworkin, entre otros. Conclusiones: el ámbito de lo mercantil tiene que ser impactado con la tendencia anunciada, pues de no serlo se tornaría un elemento excluido del contexto que se propone tan novedosa figura.

Palabras clave: derecho mercantil, doctrina económica, estado, principios. 


\title{
Legal Principles and their Evolution in Commercial Law
}

\begin{abstract}
Purpose: This essay aims to show how commercial law, as a behavior of man in society, is not alien to legal principles. Description: The fact that this legal branch is relatively new regarding its codification shows that its genesis is as old as man. Therefore, this work demonstrates how the general principles of law have permeated this specialty. Point of view: The research deals with the following legal question: How have the general principles of law permeated commercial law and how has it evolved? It is answered using the method proposed by Tomás Austin, and Frida Gisela Ortiz-Uribe and María del Pilar García. Hernán Valencia-Restrepo, Norberto Bobbio, Ronald Dworkin, among others give the theoretical basis. Conclusions: The commercial sphere must be affected by said trend; otherwise, it would be excluded from the context proposed by this new concept.
\end{abstract}

Keywords: commercial law, economic doctrine, state, principles.

\section{Os princípios e sua evolução no direito comercial}

\section{Resumo}

Propósito: este ensaio está orientado a mostrar como o direito comercial, enquanto comportamento do homem em sociedade, não é alheio à principialística. Descrição: o fato de esse ramo do jurídico ser relativamente novo no que se refere à sua codificação, evidencia que sua gênese é tão antiga quanto a humanidade. Portanto, este trabalho evidencia a forma na qual os princípios gerais do direito têm permeado essa especialidade. Ponto de vista: esta pesquisa trata da seguinte questão jurídica: de que maneira os princípios gerais do direito têm permeado o direito comercial e qual tem sido sua evolução? Desenvolve-se com base na metodologia proposta em Tomás Austin, Frida Gisela Ortiz-Uribe e María del Pilar García. O fundamento teórico é o dado por Hernán Valencia-Restrepo, Norberto Bobbio, Ronald Dworkin, entre outros. Conclusões: o âmbito do mercantil tem que ser impactado com a tendência anunciada, pois, se não for assim, se tornaria um elemento excluído do contexto que tão nova figura propõe.

Palavras-chave: direito comercial, doutrina econômica, estado, princípios. 


\section{INTRODUCCIÓN}

Este ensayo se escribe como parte de la realización de la investigación "La Evolución de los principios del derecho mercantil en el actual Estado social de derecho", en la cual se intenta resolver la cuestión jurídica planteada. El texto parte con el desarrollo de una breve ambientación del tema de los comportamientos del ser humano, puesto que a partir de aquellos es como el hombre resuelve sus necesidades. Es en este punto donde surge la explicación de la génesis del comercio, así como de la actividad mercantil del hombre en sociedad, ya que responde a una necesidad del ser humano en convivencia. Agotado lo anterior, se incursiona en avances expositivos sobre el pensamiento elemental que tuvo el hombre sobre lo económico y el desarrollo de este pensamiento a través de las diferentes doctrinas económicas y teóricas, y por posiciones ideológico-políticas y religiosas, hasta llegar a la concepción actual de lo económico en relación con el derecho mercantil. Finalmente, con el fin de completar el análisis anterior, se busca la relación entre la teorización del Estado con el factor económico de aquel, y de qué forma los principios universales del derecho toman un papel preponderante en todo este concierto conceptual que, en últimas, permite la convivencia del hombre.

\section{EL IUSNATURALISMO}

Del latín ius, "derecho", y natura, "naturaleza", es una corriente de la filosofía del derecho según la cual, al menos, una parte de las normas convencionales del derecho y la moral están asentadas en principios universales e inmutables. Este conjunto de normas conforma el derecho natural. El origen de los principios del derecho natural, dependiendo del autor, es dado por Dios, la Naturaleza o la Razón.

El derecho natural es un modelo epistemológico de la filosofía del derecho, el cual abarca desde la filosofía griega, hasta la racionalista (derecho natural clásico), del racionalismo al iuspositivismo (derecho natural neoclásico). y del iuspositivismo, a comienzos del siglo xIX, hasta la actualidad. Todo este recorrido histórico ha permitido fortalecer - en esta tendencia- la organización de los principios del derecho como respuesta natural del comportamiento del hombre en comunidad. Como ejemplo se debe citar cómo:
Hubo un gran momento en que el derecho natural se enfrentó contra el consuetudinario, en la contienda entre fray Bartolomé de las Casas y Juan Ginés de Sepúlveda por el derecho 'a sojuzgar a los indios'; posteriormente Hugo Grocio, Heinecio y Puffendorf defendieron el iusnaturalismo, y el conflicto reverdeció con el enfrentamiento entre el consuetudinarista Edmund Burke y el iusnaturalista Thomas Paine con motivo de la Revolución Francesa. ${ }^{1}$

\section{EL ESTUdiO DE LA PRINCPIALÍSTICA}

En el ejercicio de la actividad investigativa, y dado que la misma alude a los principios en el derecho mercantil, es procedente detenerse de manera ilustrativa y analítica en esta temática con el propósito de iluminar el sendero de la principialística, del cual penden - por lo menos, inicialmente- los temas fundamentales de este trabajo.

El profesor Hernán Valencia-Restrepo define de la siguiente manera principialística:

La Nomoárquica o Principialistica Jurídica hácese derivar de la dicción compuesta "Nomoárquica" de los nombres helénicos nómos (ley o derecho) y archaí (principios). A ellas se le añade el sufijo griego ica, significativo de arte, ciencia o habilidad y en nuestro caso de razonabilidad, racionalidad, cientificidad. Por consiguiente, "Nomoarquica" es la filosofía y la ciencia de los principios jurídicos. ${ }^{2}$

\section{Asimismo:}

El estudio y el desarrollo de la ciencia jurídica, debido a las complicaciones a lo largo de la historia y especialmente de la sociedad moderna, ha exigido tanto al Estado, como a los que hacen parte del sistema jurídico, numerables formas, métodos de cómo hacer que la justicia sea más rápida, efectiva y equitativa. Esta búsqueda de salidas y variaciones en la norma, han generado un gran impacto social, en la medida que no solo el Estado ha asumido la responsabilidad

1. Véase Paola Andrea Ramírez. Iusnaturalismo. 25 de septiembre de 2009. Disponible en http://teoriadelderecho14.blogspot. com/2009/09/iusnaturalismo.html

2. Véase Hernán Valencia-Restrepo. NomoÁrquiCA, PRInCIPIALÍSTICA JURÍDICA O LOS PRINCIPIOS GENERALES DEL DERECHO. Bogotá: Editorial Temis. (1993). 
de mejorar la justicia, sino que cada individuo se ha hecho parte de esta gran tarea. ${ }^{3}$

La etimología del vocablo principio es necesaria para referirse a su significado:

Valencia refiere el origen etimológico de "principio" a la palabra principium, que podría tener dos acepciones: Una primera, que significa "cabeza de una serie o primer singular de un todo plural", porque provendría de princeps, principis, "príncipe", como titular o cabeza de una magistratura. Según esta acepción, los principios del derecho son cabeza de todo ordenamiento o las primeras normas del conjunto de estas. La segunda acepción sería la de origen permanente o punto fundamental de partida de algo, porque principium provendría de principii. Y así, los principios en derecho serían normas fundamentales del sistema normativo, punto de donde surgen de modo permanente las demás normas del sistema jurídico. ${ }^{4}$

Los principios son fuentes formales generales del ordenamiento jurídico, al entender por fuentes formales aquellos procesos por los cuales se crean las normas jurídicas generales. Así, entonces, los principios consisten en un proceso creador de normas jurídicas generales. Sin embargo, existen dos definiciones de los principios generales del derecho, en las que se encuentran sus elementos estructurales, tanto los de su naturaleza filosófica, como los de su naturaleza jurídica: el principio como proceso creador de la norma principial y el principio como resultado del proceso creador o la norma principal misma. ${ }^{5}$

El principio, como proceso creador de la norma, se puede definir así: preexistencia de un valor fundamental y social, cuya aprehensión por parte de la comunidad, el pueblo o el constituyente primario le genera la convicción de obligatoriedad coercible de ese mismo valor. Y el principio como resultado del proceso creador, o bien la norma principial misma, se puede definir como norma jurídica fundamental, imperativa, universal, tópica, axiológica, explícita

3. Véase Lizandro Alfonso Cabrera Suárez. Los principios y su papel en la crisis de las fuentes del derecho. Criterio Libre juríDICo 8(1). (Enero-Junio 2011).

4. Véase Claudia Helena Forero Forero. Principios constitucionales: manifestación positiva de los principios generales del derecho (sistema jurídico colombiano: derecho en parte natural y en parte positivo). Revista Telemática de Filosofía del Derecho 6. 2002/2003. Pág.173. Disponible en http://www.rtfd.es/numero6/10-6.pdf. 5. Véase Hernán Valencia-Restrepo. Conferencia dos definiciones de los principios generales del derecho. Editorial Temis. $3^{\text {a }}$ edición. (2005). Pág. 584. o implícitamente positiva, la cual sirve para crear, interpretar e integrar el ordenamiento que, según Valencia-Restrepo, es la noción más indicada para lo que él denomina "verdaderas normas".

Norberto Bobbio se refiere al respecto en los siguientes términos:

En mi opinión los principios generales no son sino normas fundamentales o generalísimas del sistema, las normas más generales (...) Para mí es indudable que los principios generales son normas como todas las otras (...) Dos son los argumentos para sostener que los principios generales son normas, y ambos son válidos: de acuerdo con el primero de ellos, si son normas aquellas que se extractan de los principios generales por medio de un procedimiento de generalización sucesiva, no se ve por qué estos no deban ser normas también (de las especies animales obtengo siempre animales y no flores o estrellas). En segundo lugar, la función para la cual se deducen y se adoptan es la misma que se lleva a cabo para todas las normas, o sea la función de regular un caso. ${ }^{6}$

\section{En Colombia, Marco Monroy-Cabra sostiene:}

La Corte Constitucional, en la sentencia C-479 de 1992, le dio carácter vinculante al Preámbulo de la Constitución. Dice al respecto: El Preámbulo de la Constitución incorpora, mucho más allá de un simple mandato específico, los fines hacia los cuales tiende el ordenamiento jurídico; los principios que inspiraron al Constituyente para diseñar de una determinada manera la estructura fundamental del Estado; la motivación política de toda la normatividad; los valores que esa Constitución aspira a realizar y que trascienden la pura literalidad de sus artículos. El Preámbulo da sentido a los preceptos constitucionales y señala al Estado las metas hacia las cuales debe orientar su acción; el rumbo de las instituciones jurídicas.?

Por tanto, todas las normas de la Constitución, incluido el Preámbulo, son vinculantes, tanto para los servidores públicos, como para los particulares. En la Constitución, es necesario distinguir principios, valores y reglas constitucionales. Ronald Dworkin expresa que "el ordenamiento jurídico no se agota en estándares que funcionan como reglas, sino que en

\footnotetext{
6. Véase Norberto Bobbio. Teoría general Del Derecho. Editorial Temis. (1987). Págs. 239-240.

7. Véase Corte Constitucional Colombiana. Sentencia C-479 de 1992. (MP José Gregorio Hernández y Alejandro Martínez Caballero: Agosto 13 de 1992)
} 
él es posible encontrar otros que operan como 'principios, directrices políticas y otros tipos de pautas", a los cuales denomina genéricamente "principios". Estos tipos de estándares jurídicos, o bien proponen objetivos que han de ser alcanzados, o bien contienen exigencias de justicia, equidad o alguna otra dimensión de la moralidad. La diferencia entre principios y reglas es, para Dworkin, ${ }^{8}$ una diferencia lógica. Las reglas son aplicables, "a la manera de disyuntivas. Si los hechos que estipula una regla están dados, entonces o bien la norma es válida, en cuyo caso la respuesta que da debe ser aceptada, o bien no lo es, y entonces no aporta nada a la decisión". En cambio, los principios,

No establecen consecuencias jurídicas que sigan automáticamente cuando se satisfacen las condiciones previstas, puesto que ellos sólo enuncian razones, pero no exigen decisiones particulares. La doctrina ha distinguido entre valores, principios y reglas constitucionales y ha formulado, con base en precisiones de concepto, una teoría sobre la existencia de un sistema de jerarquía normativa dentro de los textos constitucionales. Los valores son considerados como normas abstractas y de tipo abierto que orientan la producción e interpretación de las demás normas, y en tal virtud fijan criterios de contenido para otras normas y por tanto prevalecen sobre los principios y sobre las reglas. Para otra parte de la doctrina, los valores son normas que, al igual que los principios, determinan el contenido de otras normas, y sólo se diferencian de éstos por su menor eficacia directa, aplicándose estrictamente en el momento de la interpretación. Los valores están formulados como cláusulas generales que determinan los criterios interpretativos del resto del ordenamiento. Los principios son normas que condicionan las demás normas, pero su grado de concreción y eficacia es mayor, al tener por sí mismos carácter normativo. Por tanto, los valores son más abstractos y abiertos que los principios. ${ }^{9}$

La posición de Bonorino es la siguiente:

Cuando los juristan razonan o discuten sobre derechos y obligaciones jurídicas, particularmente en casos difíciles, hacen uso de pautas que no funcionan como reglas, sino que operan como principios. Estos principios, que pueden ser principios en sentido es-

8. Véase Ronald Dworkin. Los Derechos en SERio, Ariel. (1995). Pág. 72. Citado por Marco Monroy-Cabra. Anuario Constitucional Colombiano. (2001). Pág. 25.

9. Id. tricto, directrices políticas u otro tipo de pautas, se diferencian de las reglas por su estructura lógica y por poseer la dimensión de peso. Son estos principios los que permiten entender la labor judicial en los casos controvertidos, como la aplicación de los derechos u obligaciones que las partes tenían con antelación a la decisión institucional. Existen dos formas de entender los principios jurídicos: a) considerando que forman parte del derecho al igual que las reglas y que por ende obligan de la misma manera que éstas, o b) negar que los principios obliguen de la misma forma que las reglas, considerándolos en consecuencia como por encima del derecho. La segunda forma de entender los principios jurídicos resulta inaceptable pues ninguno de los argumentos que pueden dar los positivistas en su apoyo es aceptable, y porque, además, lleva a sostener que ninguna regla puede ser considerada como jurídicamente obligatoria. ${ }^{10}$

\section{LAS DOCTRINAS ECONÓMICAS}

Hablar hoy de derecho mercantil como un producto científico-jurídico necesariamente exige de unos antecedentes en la convivencia humana. Por lo tanto, es procedente revisar la evolución histórica que analiza la aparición del comercio, del mercado y del intercambio de bienes, desde las épocas pretéritas hasta nuestros días. Pues es allí donde reposan los gérmenes de las ideas que tuvieron los antepasados para solventar las comunes necesidades de alimento, techo y vestido, como fundamento de los comportamientos patrones en su existencia. Tomar una decisión de ejercitar una determinada actividad - llámese pastoreo, recolección, defensa física, etc.no resulta por generación espontánea o fortuita, si no que debió requerir de una actividad racional, esto es, de una combinación de conocimientos agrupados por la experiencia, lo que les permitió tomar decisiones para solventar las necesidades. Dichas decisiones tuvieron su fermento en unos planteamientos elementales, a partir de los cuales y apoyándose en ellos, daban los pasos creadores de los nuevos conocimientos que sustentarían las actuaciones. Así, por ejemplo, es necesario conocer cuáles fueron las razones y cuáles los principios que las inspiraron, movieron al hombre a realizar el intercambio de

10. Véase Pablo Raúl Bonorino. INTEGRIDAD, DERECHO Y

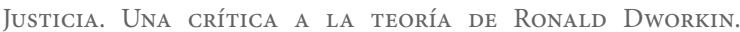
Universidad Nacional de Colombia. (2003). 
bienes y servicios, y así obtener el resultado buscado. Asimismo, cuál era la satisfacción de sus necesidades, pero sin incurrir — al lado de esa satisfacciónen un daño para sí mismo o quienes lo rodean, de modo que fue la génesis de los denominados "principios jurídicos" que positivizados o no rigieron, rigen y regirán de manera efectiva los actos humanos en pos de garantizar la convivencia humana. Es, entonces, cuando se debe entrar a comparar aquellos principios que direccionan el Estado de derecho con aquellos que acompañan la novedosa figura del Estado social de derecho. Es por esto que el marco teórico toma como eje la principialística. Inicia con una ilustración analítica de Colombia en su devenir histórico, esto es, parte de lo que sucedía en la época precolombiana, en la cual ya se ejercía una actividad de intercambio y en la que imperaban unos principios naturales garantes de la actividad comercial que ellos ejercían, principios a los que se les puede hacer una analogía o comparación con los de los gremios o corporaciones. ${ }^{11}$ Esto, sin olvidar que la evolución y su recta del tiempo fue abruptamente cortada por el descubrimiento de América, hasta llegar a las leyes de Indias y a la conformación de la Gran Colombia, lo cual permite una revisión de la paleta de posibilidades en la aplicación del derecho mercantil, para caer finalmente, a partir de 1991, en el estudio del denominado Estado social de derecho.

En la evolución histórica del derecho comercial, se encuentran dos aspectos bien delimitados: uno, la posición meramente social, o sea, del individuo que no ve más allá de este resultado al responder a sus necesidades, y otro, la posición ideológica, que la religión —en este caso, quizá con ojo avizor, presagiaba-

11. "Constituye la época en la cual se define el Derecho Mercantil como una ciencia jurídica autónoma. Su estructuración se inicia una vez que los comerciantes se asocian para cada arte, y con éstas se conciben las universidades y las corporaciones. Las corporaciones eran administradas por uno o más Cónsules, asistidos por un consejo de ancianos de reconocida trayectoria en el comercio. Se crearon normas jurídicas que fueron alimentadas por la costumbre, dando paso no sólo a los Cónsules, sino además a los Estatutarios y Estatutos. Los Estatutarios eran encargados de compilar las soluciones a los problemas por escrito, dictadas mediante sentencias por los Cónsules, para luego archivarlas en la Sede de la Corporación, dando origen a los Estatutos. La sentencia que dictaban los Cónsules eran firmes y ejecutorias, pero podían ser apelables ante un Tribunal, integrados por comerciantes elegidos por sorteo a quienes se les llamaba: Sobre-Cónsules. Las ferias también tuvieron lugar en esta época, donde los comerciantes de distintas regiones concurrían para exhibir sus mercancías, comprar o vender". Véase HomePage. EDAD MEDIA. Disponible en http://www.monografias. com/docs111/trabajo-derecho-mercantil-ii/trabajo-derecho-mercantil-ii.shtml podría generar hacia el futuro el comportamiento excesivamente ventajoso de ciertos hombres sobre otros.

La existencia del derecho comercial en la actualidad depende de circunstancias especiales en la organización jurídica de cada nación. Sin embargo, esas circunstancias obedecen a unos principios que mueven el comportamiento del individuo en la sociedad. Dado que su contenido y sus características están determinados por el progreso y la modificación constante de los efectos económicos, si se toma en cuenta que los principios son las razones fundamentales que mueven la conducta social del hombre en comunidad, la actividad mercantil de este no se escapa a tal presupuesto universal. Colombia es hoy un Estado social de derecho, situación determinada por la Carta Magna de 1991, pues durante más un siglo la Constitución del 1886 planteó que era un Estado de derecho. La anterior afirmación pareciera que abre la puerta a una escisión en cuanto a la génesis y clasificación de los principios generales del derecho, la cual permite pensar que unos son los principios que se aplican en el Estado de derecho, y otros muy distintos en el Estado social de derecho. Esta tesis se encuentra alejada de una certeza lógica, pues una cuestión fundamental en esta investigación será determinar y comprobar que los principios generales del derecho no se encuentran discriminados en cuanto a las diferentes ramas en que se estudia y se aplica ese derecho. Por tanto, al menos inicialmente, se puede aseverar que los principios en el derecho mercantil están en la misma fuente de donde emanan los principios generales del derecho, pues al final de cuentas las partes comprometidas en el ejercicio de las actividades mercantiles - pese a tener una connotación esencial en la actividad contractual, como lo es la de reportar utilidades económicas producto de los convenios- no pierden su calidad de actores de sus propios derechos en la relación en que se desempeñan; es decir, el derecho mercantil dentro de sus principios consagra la equidad en la aplicación de los derechos de las partes y proscriben el abuso de una parte sobre otra, bajo figuras muy representativas, como, por ejemplo, el aprovechamiento de la parte dominante en la negociación. Tal como se encuentra en el trabajo investigativo de Berrios:

Estado de derecho es un concepto con dos componentes; por un lado, el Estado como poder político concentrado y por otro, el derecho como conjunto de normas. El Estado de derecho es un poder limitado por el derecho. Si bien, en el Estado absolutista, el so- 
berano es el rey, él es el poder que está por encima de todos, es el que unifica todas las funciones del poder político y no admite límite ni contrapeso ni crítica; para limitar al Estado absolutista surge el Estado de derecho. En el Estado absolutista, el poder se instituye desde arriba, no surge del pueblo, sino del poder mismo, es un poder único sin divisiones ni separaciones, es un poder que inunda a la sociedad, que la domina y la avasalla; el individuo carece de fuerza frente a ese poder. La democracia forma parte de esta evolución buscando la legitimación del poder por el ciudadano, materializando así la soberanía del pueblo. ${ }^{12}$

En el Estado de derecho se contempló la actividad jurídica mercantil, desde el punto de vista de normas que hoy todavía imperan, pero parecieran ajenas a contemplar el fenómeno cuya regulación es su objetivo, a saber: el intercambio de bienes y servicios en la sociedad.

El principio de Estado Social de Derecho contrasta con el Estado de Derecho en cuanto a sus fines, puesto que aquel ya no se limita solamente a asegurar la vida, la propiedad y la libertad mediante la protección contra el fraude, el hurto, el incumplimiento contractual o los daños ocasionados por terceros, funciones típicas del Estado gendarme. Sus fines tienen mayor alcance e incluyen, entre otros, promover la prosperidad general; garantizar la efectividad de los principios, derechos y deberes consagrados en la Constitución; facilitar la participación de todos en las decisiones que los afectan y en la vida económica, política, administrativa y cultural de la Nación; y asegurar la vigencia de un orden justo (art. $2^{\circ}$ de la C. P. esto nos indica la supremacía del Estado). Para ello, el Estado cuenta con facultades amplias de intervención en la economía, las cuales han de estar orientadas a lograr los fines generales del Estado y los fines especiales de la intervención económica enunciados principalmente en el artículo 334 de la Constitución. (...) Entre estos fines especiales se destacan, el de asegurar que todas las personas, en particular las de menores ingresos, tengan acceso efectivo a los bienes y servicios básicos. ${ }^{13}$

12. Véase Martí Batres Guadarrama. Estado de derecho. LA JoRnadA. Disponible en http://www.jornada.unam. $\mathrm{mx} / 2005 / 04 / 21 /$ index.php? section $=$ politica\&article $=023 \mathrm{a} 2 \mathrm{pol}$

13. Véase Gerencie.com. Principio de Estado Social DE DereCHO. Disponible en http://www.gerencie.com/ principio-de-estado-social-de-derecho.html
Se resalta que la voluntad del constituyente en torno al Estado no se reduce a exigir de este que no interfiera o recorte las libertades de las personas; también exige que el mismo se ponga en movimiento a fin de contrarrestar las desigualdades sociales existentes y ofrecerle a todas las oportunidades necesarias para desarrollar sus aptitudes y para superar los apremios materiales. Curiosamente, las normas de derecho mercantil dentro de esta nueva concepción de Estado no han cambiado y no son diferentes a las del Estado de derecho, pero la principialística que anima a este último sí implica al aplicarlas judicialmente una nueva concepción que establece la diferencia entre los modelos. No es en la norma, es en la principialística donde está el cambio. La Corte Constitucional colombiana se ha pronunciado muchas veces sobre el tema de la principialística y sobre el bloque de constitucionalidad; ejemplo de esto son las sentencias C-225 (1995), ${ }^{14}$ C-486 (1993), ${ }^{15}$ y T-296 (1994), etc. ${ }^{16}$ La vía jurisprudencial se justifica porque es misión inherente a toda administración de justicia crear, interpretar, integrar y renovar el ordenamiento, y ello en muchas ocasiones es posible hacerlo acudiendo a los principios. Varios excelentes ejemplos para este caso son la Sentencia T-011 (1993), ${ }^{17}$ al pronunciarse sobre la buena fe; la C-112 (1993), ${ }^{18}$ sobre la igualdad ante la ley; sobre la cosa juzgada, C-543 (1992); debido proceso, T-516 (1992); ${ }^{19}$ supremacía constitucional

14. Cf. Corte Constitucional Colombiana. Sentencia C-225/95 (MP Alejandro Martínez Caballero: Mayo 18 de 1995).

15. Cf. Corte Constitucional Colombiana. SEnTENCIA C-486/93. (MP Eduardo Cifuentes Muñoz: Octubre 28 de 1993).

16. Cf. Corte Constitucional Colombiana. Sentencia t-296/94. (MP Carlos Gaviria Díaz: Junio 29 de 1994).

17. Cf. Corte Constitucional Colombiana. Sentencia T-011/93. (MP Alejandro Martínez Caballero: Enero 18 de 1993).

18. Cf. Corte Constitucional Colombiana. Sentencia C-112/93. (MP Hernando Herrera Vergara: Marzo 25 de 1993).

19. "El carácter fundamental del derecho al debido proceso proviene de su estrecho vínculo con el principio de legalidad al que deben ajustarse no sólo las autoridades judiciales sino también, en adelante, las administrativas, en la definición de los derechos de los individuos. Es pues una defensa de los procedimientos, en especial de la posibilidad de ser oído y vencido en juicio, según la fórmula clásica, o lo que es lo mismo, de la posibilidad de ejercer el derecho de defensa. El derecho al debido proceso comprende no solo la observancia de los pasos que la ley impone a los procesos judiciales y a los procesos y trámites administrativos, sino, también el respeto a las formalidades propias de cada juicio, que se encuentran, en general, contenidas en los principios que los inspiran, el tipo de intereses en litigio, las calidades de los jueces y funcionarios encargados de resolver". Véase Corte Constitucional Colombiana. Sentencia T-516/92. (MP Simón Rodríguez-Rodriguez, Fabio Moron, Jaime Sanin: Septiembre 15 de 1992). 


\section{C-574 (1992), ${ }^{20}$ y T-614 de 1992; ${ }^{21}$ especialidad, C-543 de 1992; ${ }^{22}$ favorabilidad, C- 438 de 1992; ${ }^{23}$ presunción}

20. "Pese al trámite sui generis y de carácter excepcional que sufrieron por razón del tránsito constitucional, estos constituyen verdaderos tratados en vías de formación, pues con respecto a ellos aún no se ha producido su perfeccionamiento, toda vez que con anterioridad a su revisión por la Corte el ejecutivo no había manifestado el consentimiento en obligarse por ellos en el ámbito internacional. Como tales están sometidos al control de constitucionalidad previsto en el numeral 10 del artículo 241 de la Carta. El control previo, automático e integral garantiza por un lado el cumplimiento de los compromisos internacionales que es corolario de ineludible observancia por haber adherido Colombia a las normas de convivencia entre las naciones civilizadas una de las cuales precisamente es la conocida como Pacta Sunt Servanda. Por otro, asegura el respeto y la observancia del Estatuto Fundamental por sus autoridades inclusive cuando desarrollan funciones en el plano internacional, pues no se remite a duda que la supremacía de la Constitución que se consagra en el Artículo 4 de la misma no admite sino las excepciones que la propia Carta establece". Cf. Corte Constitucional Colombiana. Sentencia C-574/92. (MP Ciro Angarita Barón: Octubre 28 de 1992).

21. "Puede suceder que el ataque contra el derecho fundamental o la amenaza que se cierne sobre él provengan de la aplicación que se haya hecho o se pretenda hacer de una norma -legal o de otro nivel- que resulta incompatible con la preceptiva constitucional. En esa hipótesis es indudable que surge la posibilidad de ejercitar en forma simultánea la llamada excepción de inconstitucionalidad y la acción de tutela, la primera con el objeto de que se aplique la Constitución a cambio del precepto que choca con ella, y la segunda con el fin de obtener el amparo judicial del derecho. La vigencia de la norma no se controvierte, ni tampoco se concluye en su inejecutabilidad o nulidad con efectos "erga omnes". Apenas ocurre que, con repercusión exclusiva en la situación particular, se ha desvirtuado la presunción de constitucionalidad; ella seguirá operando mientras no se profiera un fallo del tribunal competente que defina el punto por vía general". Véase Corte Constitucional Colombiana. Sentencia T-614/92. (MP José Gregorio Hernández: Diciembre 15 de 1992).

22. "La cosa juzgada, que confiere a las providencias la fuerza de verdad legal dentro del ámbito individualizado del asunto litigioso resuelto, se funda en el principio de la seguridad jurídica, la cual para estos efectos, reside en la certeza por parte de la colectividad y sus asociados en relación con la definición de los conflictos que se llevan al conocimiento de los jueces. El principio de la cosa juzgada hace parte indiscutible de las reglas del debido proceso aunque no se halle mencionado de manera expresa en el artículo 29 de la Constitución. Todo juicio, desde su comienzo, está llamado a culminar, ya que sobre las partes no puede cernirse indefinidamente la expectativa en torno al sentido de la solución judicial a su conflicto. En consecuencia, hay un verdadero derecho constitucional fundamental a la sentencia firme y, por tanto, a la autoridad de la cosa juzgada". Véase Corte Constitucional Colombiana. Sentencia C-543/92. (MP José Gregorio Hernández: Octubre 1 de 1992).

23. Cf. Corte Constitución Colombiana. Sentencia C-280/96. Fundamento 3. (MP Alejandro Martínez Caballero: Junio 25 de 1996). En el mismo sentido, véanse también las sentencias T-438 de 1992; C-417 de 1993; C-251 de 1994; C-244 de 1996; Y C-769 de 1998. de inocencia, c-599 de $1992 ;{ }^{24}$ y T-097 de $1994 ;{ }^{25}$ celeridad, T-531 de 1992; ${ }^{26}$ jerarquía, C-543 de 1992; ${ }^{27}$ prevalencia del derecho internacional C-019 de 1993; ${ }^{28}$

24. "La presunción de inocencia es una presunción juris tantun que admite prueba en contrario. Tal presunción cabe ciertamente tanto en el ámbito del derecho penal como en el de las infracciones administrativas. Naturalmente como surge de la lógica del proceso, la carga de la prueba está a cargo del Estado, sin perjuicio de que los acusados también ejerzan la iniciativa probatoria a fin de buscar el esclarecimiento de los hechos". Véase Corte Constitucional Colombiana. Sentencia C-599/92. (MP Fabio Morón Díaz: Diciembre 10 de 1992).

25. "El principio de la presunción de inocencia impone que la carga de la prueba corresponda a los acusadores y que para desvirtuarla sea necesario que la prueba practicada haya tenido lugar en un juicio, con todas las garantías procesales y formalidades previstas. Para condenar es indispensable la certeza de la culpabilidad, debido a que es la inocencia la que se presume cierta. La culpabilidad debe ser probada bajo las condiciones establecidas por el debido proceso. Cualquier enunciado con pretensión de veracidad establecido por fuera de las formas procesales que protegen el derecho de defensa, es una veracidad espuria que no tiene validez, así cuente con la convicción del juzgador o incluso con la verdad real. Mientras estos supuestos no hayan sido respetados, el investigado continuará gozando del beneficio de la presunción de inocencia". Véase Corte Constitucional Colombiana. SENTENCIA T-097/94. (MP Eduardo Cifuentes Muñoz: Marzo 7 de 1994).

26. "El carácter de orden público de las normas sobre menores y la interpretación de las mismas, obligan al juez de familia a impulsar oficiosamente el proceso, no limitándose a decretar las pruebas solicitadas en su oportunidad por las partes sino todas aquellas que conduzcan al esclarecimiento de las circunstancias de posible abandono o peligro del menor. De otra parte, la no valoración por el juez de las pruebas en la sentencia puede configurar una causal de inconstitucionalidad por carencia de motivación de la decisión judicial. En los procesos de privación, suspensión o rehabilitación de la potestad parental, el juez de familia está dotado de amplios poderes para intervenir en defensa de sus intereses, entre ellos se cuenta la posibilidad de iniciar oficiosamente el proceso. Véase Corte Constitucional Colombiana. Sentencia T-531/92. (MP Eduardo Cifuentes Muñoz: Septiembre 23 de 1992).

27. "La cosa juzgada, que confiere a las providencias la fuerza de verdad legal dentro del ámbito individualizado del asunto litigioso resuelto, se funda en el principio de la seguridad jurídica, la cual para estos efectos, reside en la certeza por parte de la colectividad y sus asociados en relación con la definición de los conflictos que se llevan al conocimiento de los jueces. El principio de la cosa juzgada hace parte indiscutible de las reglas del debido proceso aunque no se halle mencionado de manera expresa en el artículo 29 de la Constitución. Todo juicio, desde su comienzo, está llamado a culminar, ya que sobre las partes no puede cernirse indefinidamente la expectativa en torno al sentido de la solución judicial a su conflicto. En consecuencia, hay un verdadero derecho constitucional fundamental a la sentencia firme y, por tanto, a la autoridad de la cosa juzgada". Véase Corte Constitucional Colombiana. Sentencia C-543/92. (MP José Gregorio Hernández: Septiembre 23 de 1992).

28. "La doble instancia no pertenece al núcleo esencial del debido proceso, - pues la ley puede consagrar excepciones-, salvo cuando se trata de sentencias condenatorias, las cuales siempre podrán ser impugnadas. El concepto de "sentencia condenatoria" contradice la filosofía y naturaleza de la legislación de menores, a cuyo amparo, 
primacía de los derechos fundamentales T-533 de $1992 ;{ }^{29}$ autonomía del juez, C-543 de $1993 ;{ }^{30}$ y el derecho a la defensa, T-097 de 1994.

En las épocas remotas, dada la necesidad de resolver inconvenientes con la naturaleza, el hombre requirió de la intervención de sus congéneres para ello. Así, a fin de satisfacer la urgencia de adquirir alimento y vestido, debió enfrentarse a la caza como actividad que le produciría satisfacción a elementales requerimientos, ejercicio que no pudo adelantar individualmente, y debió acudir a la ayuda y colaboración de sus semejantes. Este hombre cazador, que obtuvo como producto más de lo que necesitaba y podía consumir, pronto entendió que ese excedente la permitía iniciar una actividad de intercambio con sus semejantes, quienes desarrollaban otra actividad como la de recolectar frutas y, seguramente, también les sobraba algo y lo podían canjear. Surge aquí el concepto de trueque, eso sí, sin considerarlo aún una actividad de comercio como tal: era el cambio por el cambio. En este actuar aparentemente ingenuo

el juez puede imponerle medidas al menor infractor de carácter protector y pedagógico, pero nunca de naturaleza condenatoria. Sin embargo, si alguna de esas medidas es privativa de la libertad, podrá ser siempre impugnada a la luz de la Convención sobre los Derechos del Niño, que, ha sido incorporada a nuestra legislación interna. Todo lo cual se reafirma, además, con el artículo 93 de la Carta, que establece que los tratados y convenios internacionales - ratificados por el Congreso- que reconocen los derechos humanos, prevalecen en el orden interno. El artículo 167 del Código del Menor habrá de entenderse en el sentido de que los procesos relativos a menores infractores de la ley penal son de única instancia, salvo en los casos en los que durante su transcurso o al final del mismo se tome una medida que, - si bien protectora o pedagógica一, sea privativa de la libertad. Dichas medidas podrán ser objeto de impugnación ante una instancia superior, sin perjuicio de los recursos de reposición que el mismo Código ya contempla. Véase Corte Constitucional Colombiana. Sentencia C-019. (MP Ciro Angarita: Enero 25 de 1993).

29. Corte Constitución Colombiana. El Estado social de derecho, instituido por el constituyente colombiano, define la naturaleza del régimen político, económico y social, identificándolo con los valores y fines enunciados en el Preámbulo de la Constitución. La superación del Estado de derecho como garantía de la libertad y de la igualdad formales tiene lugar en el Estado social de derecho mediante la acentuación de los elementos finalistas que guían la actividad estatal administrativa y política. La persona humana y su dignidad constituyen el máximo valor de la normatividad constitucional, cuyo reconocimiento conlleva importantes consecuencias para el sistema de relaciones económicas y sociales. Véase Corte Constitucional Colombiana. Sentencia T-533/92. (MP Eduardo Cifuentes Muñoz: Septiembre 23 de 1992).

30. "Por su origen, las normas sustanciales y procesales tienen igual jerarquía. La primacía del derecho sustancial, en principio, no obliga al legislador, sino a los encargados de administrar justicia. En realidad, podría decirse que el artículo 228 contiene una regla de interpretación, dirigida al juez". Véase Corte Constitucional Colombiana, supra, nota 29. del hombre se encuentran inmersos unos principios naturales del comportamiento humano, tales como el de la favorabilidad, la solidaridad, etc., los cuales en últimas buscan el bienestar del conglomerado. Estos puntos de partida comportamentales inspiran posteriormente las normas que positivizaron los comportamientos modelo en el derecho mercantil.

El avance organizacional del hombre permitió la formación de grandes comunidades denominadas "pueblos", y en ellos se sintió una mayor presión por satisfacer la necesidad del intercambio de bienes y servicios. Los primeros que intentaron una actividad comercial propiamente dicha fueron los pueblos asirios y fenicios, quienes incluso estructuraron una recopilación de usos y costumbres sobre el comercio marítimo: Lex rhodia djactu. ${ }^{31}$ Ejemplo de este acrecimiento en la estructura comercial es el pueblo fenicio, el cual buscó, aprovechando la experiencia en la actividad marítima, compensar la diferencia entre sus recursos naturales y la de sus vecinos, en cuanto una variedad de productos que iban desde los minerales hasta los vegetales y animales, pero todo a nivel de intercambio, sin usar aún valores representativos. Esta labor requirió de otra paralela como lo fue la de proteger los barcos que llevaban las mercancías, de modo que crearon naves de guerra para ello, lo que permitió fundar nuevas organizaciones en islas que fueron poblando paulatinamente. Para los fenicios, el principio de su actividad comercial de intercambio de mercancías estuvo regido por la compensación, esto es, el intercambio equitativo de las cosas, lo cual sugirió por primera vez valorar la mercancía. No obstante, el éxito de sus expediciones marítimas les permitió iniciar la acumulación o atesoramiento de mercancías, lo que los convirtió en su época en el pueblo más rico de la región, e hizo nacer el espíritu especulativo que bien pronto los llevo a la piratería.

El comercio ocupó para la India un puesto preponderante, toda vez que tal actividad no se superponía a la jerarquización social por castas, y se encontró que este lo podía ejecutar solo una casta especial conformada por agricultores, industriales y mercaderes sin límite alguno; tal era el valor que el comercio tenía para aquella organización social, la cual fue discriminatoria en cuanto a su ejercicio. El principio que aplicaron los indios para comerciar fue

31. "Lex Rhodia de iactu' que en realidad estaba basada en el principio de la 'avería gruesa', tal como todavía existe en el seguro marítimo, donde los dueños de la carga y los propietarios del barco soportan conjuntamente una pérdida”. Véase Alfredo Cogorno. Elementos del seguro. HerrerA - DKP. Disponible en http://www. hdkp.pe/sp/informacion/elementos_del_seguro.html 
el de procurar bienestar para todos los asociados, lo que implicaba para quienes ejercían el comercio una posición de privilegio frente a los demás.

El pueblo egipcio, gran productor, en especial de trigo, fue prolífico en cuanto al comercio al interior de su territorio, pero por problemas religiosos no pudo inicialmente tener actividad comercial a través del mar, al que consideraba impuro. Por lo tanto, la gran cantidad de sus productos lo hicieron muy ricos y poderosos ante los demás, y esto les dio ventaja frente a la comercialización. El principio que rigió para ellos fue el de intercambiar con un valor adicional - el de la calidad-, habida cuenta de que se convirtió en uno de los cuatro grandes productores de grano del mundo. Hasta aquí, ninguna de estas organizaciones humanas contó con un derecho mercantil codiciado, simplemente produjeron normas consuetudinarias que se aplicaron por muchísimo tiempo.

Roma incorporó dentro de su modelo normativo las Leyes Rodias, lo cual se reflejó entonces en una especie de institución mercantil, inmersa dentro del ius civile. Ahora, si bien es cierto esto no permite hablar de una actividad mercantil independiente del resto del derecho, si aparece como una especialidad dentro de ese derecho, dada la necesidad apremiante que impuso el continuo ejercicio de esa actividad. Se incorporan al derecho mercantil en Roma los principios que regían para el ius civile, por ejemplo, la equidad en la contratación, y en pos de esta crearon medios y mecanismos a fin de combatir la corrupción en el comercio, instaurada por pueblos antiguos que vieron en esta no solo la forma de satisfacer necesidades, sino la manera de surgir como poderosas fuerzas de dominación mediante la especulación, la acumulación de riqueza y el atesoramiento injusto de bienes. Con esto favorecieron a pueblos menesterosos que no habían tenido acceso igualitario a la actividad mercantil, e impulsaron ferias y encuentros de comerciantes. Curiosamente, en Roma, a diferencia de India, la actividad de los comerciantes se prohibió a los patricios por ser considerada una actividad humillante, tal como lo estipulo la lex flaminia. ${ }^{32}$

32. "Probablemente para reforzar la presencia romana en el territorio galo-piceno conquistado a los senones, el tribuno Cayo Flaminio logró que se aprobara la Lex Flaminia de agro Piceno et Gallico, que contemplaba la distribución viritana de estas tierras, es decir, la asignación de parcelas individuales a ciudadanos romanos. La iniciativa del tribuno contó con la hostilidad del Senado, renuente a que se establecieran ciudadanos romanos en un área tan alejada de su centro político, con las imprevisibles consecuencias que esto podía suponer para el orden político y constitucional de Roma". Véase Arte historia. Conquista de la Galia Cisalpina. Disponible en https://www.artehistoria.com/es/contexto/conquista-de-la-galiacisalpina
El derecho mercantil en la Edad Media toma cuerpo científico. ${ }^{33}$ Esto es, inicia un proceso de identificación y autonomía que, con el transcurso del tiempo y hasta nuestros días, le ha valido una figuración de importancia en el derecho que, con la globalización, incluso le ha generado un estatus propio que trasciende las fronteras de los Estados. Frente a la limitación que tenía el derecho común y, en general, para resolver los problemas surgidos entre las relaciones de comerciantes, debido a que esta actividad fue muy próspera para la época, exigieron la conformación de una normatividad que, nacida de la costumbre, imprimiera una seriedad y, sobre todo, seguridad en la solución de los conflictos que de forma frecuente presentaba el grupo de mercaderes. Se adelantaron un sinnúmero de estatutos y reglas escritas que usaban unas instituciones denominadas "consulados", a cuya cabeza los cónsules hacían las veces de administradores de justicia en las lides del comercio. Como se puede apreciar, las normas nacen de comportamientos repetitivos que asumían los mercaderes en sus gestas cotidianas; por lo tanto, es pertinente concluir que, en la Edad Media y a través de la influencia de las Leyes Rodias, inmersas en el ius civile romano, y en ese entonces insertas en los estatutos del comercio, los principios jugaron un papel esencial en esa red estatutaria y en los principios contenidos en los diarios comportamientos que debía adelantar el mercader en el ejercicio de su actividad. Así, los administradores de justicia que con estatuto en mano resolvían los problemas habidos entre los comerciantes, aplicaban los principios como fuente normativa para dirimir los conflictos y problemas entre ellos generados. López-Rodríguez señala:

En las corporaciones se crearon tribunales especiales para dirimir las controversias que se suscitaban entre sus agremiados. La justicia era aplicada por los cónsules, con recursos ante súper-cónsules y, en algunos casos, ante la asamblea. Desde luego, todos eran comerciantes, no versados en Derecho pero, como para resolver las controversias se aplicaban los usos y costumbres formados en la práctica del comercio, estos jueces comerciantes estaban en condiciones de fallar. ${ }^{34}$

33. "El Derecho comercial nace, como rama separada del Derecho civil, en la segunda mitad de la Edad Media (baja Edad Media) - como un Derecho separado, elaborado por los comerciantes y para los comerciantes-. Los comerciantes fueron formando su propio Derecho, basado en las prácticas y costumbres". Véase Carlos López Rodríguez. El Derecho Comercial en la Edad Media. Disponible en http://www.derechocomercial.edu.uy/ RespDerechoComEdadMedia.htm

34. Id. 
Se inicia entonces con estos procedimientos la incursión de personas en una "administración de justicia especial”, quienes ajenas a una condición profesional de abogados o juristas, resuelven conflictos mediante normas que - cabe reiterar-, están conformadas por principios tales como la equidad, la buena fe y el respeto por el colega:

Paralelamente a los tribunales de cada ciudad, existían los Tribunales de Feria que, también, aplicaban la costumbre. Las sentencias que dictaban unos y otros, sirvieron para fijar el Derecho consuetudinario. El procedimiento mercantil se basó en la equidad, entendida como la búsqueda de la verdad real más que la formal. Se impuso al juez examinar el caso concreto y, después de conocido, aplicar el Derecho consuetudinario teniendo en cuenta la buena fe. ${ }^{35}$

Este proceso de positivización de las costumbres, al compilarlas en los estatutos que fueron organizados por los denominados "cónsules", es la base del andamiaje sistemático del derecho comercial consuetudinario, el cual resulta ser el origen de la denominada lex mercatoria. ${ }^{36}$ Conviene precisar que, desde siempre, la actividad de comercio y sus ejecutores erigieron con ello unos estatutos que los diferenciaba del resto de la sociedad, pues como ya se mencionó, dado que en Roma solo algunos de sus asociados podían adelantar tal actividad (al igual que en la India), estado de cosas que se conservó hasta la Edad Media. En esta, los comerciantes frecuentaron las ferias para realizar su actividad mercantil, y es allí en donde tiene su origen, tanto la costumbre en la realización de los actos de comercio, como en la forma y los métodos de negociar y de solucionar los inconvenientes que en el desarrollo de la labor se fueran presentando. En estas ferias no aparecían los señores feudales, por consiguiente, todo este acontecer que conllevó a la positivización de la costumbre fue ajena al derecho común y se realizó a sus espaldas, característica esta que le dio el sello de

\footnotetext{
35. Id.

36. "No obstante su origen consuetudinario, la Lex Mercatoria se plasmó por escrito (v.g.: Consuetudines de Genova, 1056; Constitutum usus de Pisa, 1161; Liber consuetudinum de Milán, 1216), luego se recogió en Estatutos Corporativos (como el del Arte de la Lana de Florencia, 1301; el Breve Mercatorum de Pisa, 1316; los Statuti dei mercanti de Parma, Piacenza, Brescia, Roma, Verona, Milán, etc.) y estos a su vez se integraron en tratados interlocales e internacionales (v. g.: Capitulare nauticum de Venecia; las Tavole amalfitane; los ordenamientos de Trani; el Breve Curiae maris de Pisa, entre otros)". Véase Walter René Cadena-Afanador. Impacto en Colombia de la Lex Mercatoria. Revista Civilizar 7(12). 2007. Págs. 4. Disponible en http://www.redalyc.org/ pdf/1002/100220305013.pdf
}

independencia que aún está presente en el derecho comercial. La lex mercatoria, en consecuencia, es un conjunto de compilaciones consuetudinarias y sistematizadas que, en reemplazo de los estatutos comerciales, perfeccionó las relaciones comportamentales de los mercaderes y les dio el estatus que requerían para el auge que el comercio vivió en la segunda mitad del Medioevo. Esta lex mercatoria se convierte en un producto evolutivo de la positivización normativa que en el comercio habrá de producirse más adelante en la historia. Las características de esta fueron: "La Lex Mercatoria se caracterizó por ser cosmopolita, transnacional, consuetudinaria y clasista (dirigida, de manera exclusiva, hacia la societatem mercatorum). Su cosmopolitismo se basó en la flexibilidad, especialidad (entendida como Derecho de clase) y autonomía". ${ }^{37}$

El hombre, en su continua lucha por el bienestar propio y el de sus congéneres, realiza acciones que fortalecen en lo político los Estados modernos, las libertades individuales y la protección inicial de los derechos humanos. Es así como lo amplio y general de la lex mercatoria se volvió en su contra; ahora se le apuesta a un derecho propio, iniciándose el decaimiento en lo aplicacional de este compendio legislativo en los albores del siglo XVII.

En la Edad Moderna, se le da mayor fuerza a la codificación que al estatus de mercader y comerciante que hasta ahora se había ganado. La Revolución francesa influenció el desarrolló marcado de la normatividad organizada y sistematizada en códigos. Napoleón Bonaparte, con el ánimo de dejar atrás cualquier vestigio de reglas y estatutos que anquilosaron el desenvolvimiento del derecho en la antigüedad, se propuso de manera ordenada elaborar el conocido Código Napoleónico. Este, entre otras cosas, representó la sistematización en un sólo cuerpo legal de toda la normativa mercantil. Gracias al Código se desarrolló la Doctrina Objetiva del Derecho Comercial o Mercantil. Con este código - entró en vigencia en 1808-, se le da gran importancia a todo lo concerniente a los actos de comercio como tales, tenidos como de menor valía frente al comportamiento del mercader, lo cual se había tenido en cuenta en la lex mercatoria, razón que permitió establecer específicas competencias para la administración de justicia en lo mercantil. A partir de este código, varios Estados se preocupan por ordenar la actividad mercantil y organizan sus propias codificaciones. Unas con fundamento para su desarrollo en lo objetivo del derecho mercantil (actos de comercio), en tanto que otras privilegiaron el concepto subjetivo de la actividad (comportamiento del mercader); ejemplo de la primera es

37. Id. 
el Código Napoleónico y de la segunda, el código de comercio del otrora Imperio alemán.

El derecho mercantil ha sido el impulsor del desarrollo de un concepto que ha impactado la humanidad, como lo es la globalización. Se puede afirmar que, como dicción, ${ }^{38}$ es de reciente acuñación (última década), aun cuando su significación, se tendría que aceptar que es de vieja data, casi tan antigua como el hombre, por cuanto este fenómeno ha aparecido y estado presente en los procesos comportamentales de la humanidad, generado por los actos propios de su naturaleza, como son: la ambición, el poder, el desarrollo de la curiosidad, el avance del conocimiento en la búsqueda de nuevas y mejores formas de ejercitar su existencia, etc., con los cuales ha buscado satisfacer sus intenciones, que van desde la dominación (colonialismo, ${ }^{39}$ imperialismo, ${ }^{40}$ expansionismo, ${ }^{41}$

38. "Globalización. 4. F. Econ. Proceso por el que las economías y mercados, con el desarrollo de las tecnologías de la comunicación, adquieren una dimensión mundial, de modo que dependen cada vez más de los mercados externos y menos de la acción reguladora de los Gobiernos". Véase Real Academia Española. Globalización. RAE.COM. Disponible en http://dle.rae.es/?id=JFCXg0Z.

39. "El colonialismo es el dominio territorial, económico y cultural establecido durante largo tiempo sobre un pueblo extranjero que se ve sometido al país dominante. Aunque este término existe desde la época de la Antigua Grecia, hay variantes en su significado, pues en el caso de las antiguas colonias griegas o en el de América se usaba más bien la palabra 'colonización' en vez de colonialismo, ya que en estos casos los territorios colonizados no estaban subordinados a la metrópoli, y a todos los habitantes de estos primeros se les consideraba como otros ciudadanos más de la potencia europea. En la edad contemporánea se identifica más con la dominación política de gentes de otra raza que habitan en un territorio separado por el mar de la potencia colonial, que generalmente suele ser un país europeo. El colonialismo europeo moderno comenzó en el siglo XV con los viajes de los portugueses a lo largo de la costa oeste de África. Junto con los españoles, fueron los primeros en establecer sus colonias en ultramar, y se aferraron a ellas incluso después de que su fuerza imperialista se hubiera perdido. Sin embargo, el colonialismo alcanzó su momento de máxima importancia desde finales del siglo xIx hasta mediados del xx. Los países europeos que más protagonismo tuvieron en este proceso fuero Inglaterra, Francia y Alemania, que se repartieron el continente africano (donde tan sólo quedaron dos países independientes: Liberia y Abisinia) e intentaron extender sus zonas de influencia por diferentes zonas del mundo como Europa Oriental, Oriente Medio, Extremo Oriente o el Caribe. Países como Italia, España, Portugal y Bélgica también intentaron llevarse su parte en este reparto, aunque no consiguieron tantos territorios". Véase Gabriel Tortella. LA REVOLUCIÓN DEL SIGLO XX. Taurus. (2000). Págs. 51-74.

40. "En el mundo antiguo, la práctica del imperialismo daba como resultado una serie de grandes imperios que surgían cuando un pueblo, que generalmente representaba a una determinada civilización y religión, intentaba dominar a todos los demás creando un sistema de control unificado. El imperio de Alejandro Magno y el Imperio Romano son destacados ejemplos de esta modalidad". Véase Enciclopedia Microsoft Encarta 97. Disponible en http:// mural.uv.es/martete/imper.htm

41. "El imperialismo europeo de comienzos de la era moderna (1400-1750) se caracterizaba por ser una expansión colonial en y neocolonialismo ${ }^{42}$ hasta el supuesto proteccionismo de sus relaciones: socialismo, comunismo y mercantilismo.

Existen múltiples definiciones que podrían incluso entenderse como metáforas del concepto de globalización, según las describe Octavio Lanni: "economía-mundo", "sistema mundo", "aldea global, tecno-cosmos", "planeta tierra", "hegemonía global”, entre otras, que expresan un fenómeno totalizador y complejo de la realidad internacional:

Un fenómeno que sorprende, encanta y atemoriza (...) [donde] la imaginación multiplica metáforas, símbolos, imágenes, figuras y alegorías, destinadas a dar cuenta de lo que está sucediendo. Son múltiples las posibilidades abiertas al imaginario científico, filosófico y artístico cuando se descubren los horizontes de la globalización en el mundo y éstos envuelven cosas, gentes e ideas, interrogaciones y respuestas, nostalgias y utopías. ${ }^{43}$

territorios de ultramar. No se trataba de un país que intentaba unificar el mundo sino de muchas naciones que competían por establecer su control sobre el sur y sureste de Asia y el continente americano. Los sistemas imperialistas se estructuraron de acuerdo con la doctrina del mercantilismo: cada metrópoli procuraba controlar el comercio de sus colonias para monopolizar los beneficios obtenidos". Véase Enciclopedia Microsoft Encarta 97.

42. "Política de los estados imperialistas dirigida a conservar la explotación colonial de los países débilmente desarrollados en el aspecto económico con el fin de anular las consecuencias de la desintegración del sistema colonial del imperialismo. Lenin indicó que 'el capital financiero y su correspondiente política internacional... crean toda una serie de formas de transición de dependencia estatal. Lo característico del fenómeno estriba en la variedad de formas de 'países dependientes, política y formalmente independientes, pero en realidad envueltos en las redes de la dependencia financiera y diplomática'. Para alcanzar los fines indicados los imperialistas establecen diferentes tipos de dependencia económica y política. Organizan bloques político-militares agresivos (o.T.A.N., S.E.A.T.O., C.E.N.T.O. y otros) que actúan en calidad de colonizadores en grupo; sostienen una política de expansión económica (empréstitos imperialistas, intercambio no equivalente, 'ayuda técnica'); organizan la intervención directa en los asuntos internos de los estados jóvenes, ejercen una acción ideológica sobre las masas, dedicando lugar especial al anticomunismo. Al socaire de la 'ayuda', procuran mantener, en los países liberados del imperialismo, las viejas posiciones y ocupar otras, ampliar sus puntos de apoyo social, atraerse a la burguesía nacional, implantar regímenes militares despóticos, asentar en el poder a títeres sumisos. A la política neocolonialista de las potencias imperialistas, se opone la creciente fuerza del movimiento de liberación nacional apoyado por los países socialistas". Véase Borísov, Zhamin y Makárova. Diccionario de economía política. EumED.NET. Disponible en http://www.eumed.net/cursecon/dic/bzm/n/neocolonialismo.htm

43. Véase Octavio Lanni. Teorías de la globalización. Siglo XXI. (1996). Citado por Miguel Ángel Vásquez-Ruiz. Economía Y Sociedad, Documentos de Trabajo Número 3. Agosto de 1997. 
El hombre siempre ha pretendido, por diversas razones, eliminar la diseminación y la disgregación del ser humano. Para lograr su unión e integración, por ejemplo, procura buscar un mismo idioma (torre de Babel), inventar los distintos medios de transporte para acercar los pueblos, crear las ciudades, etc. Asimismo, desde tiempos remotos y ante el ansia de poder, ha aplicado la fuerza y los métodos como el de la guerra para ganar tierras y someter pueblos enteros, apropiándose de sus culturas y demás; sin embargo, curiosamente, ninguna de estas acciones admite haberlas realizado con fines distintos a los de procurar la agrupación del ser humano y la tranquilidad de la convivencia. Ahora bien, de lo que no queda la menor duda es que todos esos actos llevan implícito un trasfondo económico totalmente evidente y que llama poderosamente la atención.

El hombre, en sus esfuerzos por resolver sus necesidades y aprovechando la evolución de los medios de transporte, intensificó una actividad como la del comercio, y acercó pueblos, culturas, pensamientos, etc., ejercicio que fue tornándose cada vez más interesante para la historia del ser humano, tal como se explicó en líneas previas. Cuando se presenta ese desbordamiento de la actividad mercantil en la segunda mitad de la Edad Media, dentro de estos intentos, uno muy efectivo y de altísimo impacto, ha sido el de las invenciones de las nuevas tecnologías en sistemas de información y comunicación (TIC), ${ }^{44}$ cuya velocidad vertiginosa no ha dado tiempo de asimilarlas o contextualizarlas, de modo que se precipitan sobre el mundo e imponen un nuevo ritmo de vida, prácticamente, una nueva era. ${ }^{45} \mathrm{Nada}$ mejor que realizar el tan anhelado sueño de acortar las distancias entre los seres que poblamos este planeta, pero... ¿A qué precio?

44. "En la actualidad la idea de que las tecnologías de la información y la comunicación tienen un gran peso en el desarrollo económico de las sociedades avanzadas está muy extendida. De hecho, este campo constituye el núcleo principal del sector de la alta tecnología (high-tech), el cual integra fundamentalmente las industrias dedicadas a la medicina, ordenadores, componentes electrónicos, la comunicación, el procesamiento de datos y la investigación aplicada". Véase Juan de Pablos Pons. LAs tecnologías DE LA INFORMACIÓN Y LA COMUNICACIÓN: UN PUNTO DE VISTA EDUCATIvo. Disponible en https://webs.ucm.es/info/multidoc/multidoc/ revista/num8/jpablos.html

45. McLuhan menciona que el "mundo se ha convertido en Aldea Global" en la que los individuos no han cambiado externamente, pero pueden comunicarse en segundos a los lugares más distantes del planeta, el producto que se consume puede estar siendo financiado por un país, diseñado y programado en otro y fabricado por un tercero, distribuido desde un cuarto país y vendido en todas las ciudades de la tierra. Véase http://www.marshallmcluhan.com/ main.htmL
Si era asombroso el invento de la radio, el teléfono y la televisión, ¿qué no se experimentará con la nueva tecnología? Con esta, prácticamente, se puede confirmar el viejo dicho de "este mundo es un pañuelo", pues las grandes distancias en el planeta, de manera increíble, han sido superadas: en cuestión de minutos, se hace un negocio mercantil entre países con ubicación antípoda y de manera asombrosa se puede mercadear, casi simultáneamente, en varios continentes; basta para ello un sistema denominado Internet ${ }^{46}$ el cual hoy tiene revolucionado el mundo, impone un ritmo de vida completamente distinto al que se traía, revalúa muchos conceptos y crea otros que han inundado el campo de la cultura, de la política y de lo social, etc., pero especialmente el de lo económico, y, naturalmente, con ellos el campo del derecho. En este último, se encuentran desesperados esfuerzos por acompasar normas y disposiciones con tan asombrosos avances, en temas tales como los que señala Plaza-Penades:

La protección de datos, la contratación electrónica, delitos informáticos, los derechos de propiedad intelectual e industrial en Internet, la resolución judicial y extrajudicial de conflictos (causados por el uso de Internet) o la incidencia de las nuevas tecnologías en el funcionamiento de las sociedades o en el de las relaciones laborales. ${ }^{47}$

Asuntos estos que surgen y generan conflictos que deben ser resueltos de manera urgente a fin de mantener la convivencia.

Todo lo anterior sugiere formular preguntas orientadoras de la siguiente manera: Frente a los avances narrados, los principios generales del derecho, especialmente en lo referente al comercio, ¿han quedado atrás?, ¿se siguen aplicando?, ¿se deben reformar?

Movido por estas curiosidades tan urgentes, y porque el derecho no se quede atrás de frente a ese impulso tan fuerte, el hombre estudioso de tan

46. El Internet admitiría ser considerado como medio frío, pues la impresionante interactividad de sus usuarios representa uno de los principales elementos distintivos del medio que admite ser considerado como inteligente. Evidentemente, en cada herramienta de comunicaciones de Internet - los chats, los weblogs o el correo electrónico, por ejemplo-, se tendrían que matizar grados. Las comunidades sensibles de Internet han convertido a Marshall McLuhan en referente obligado. Véase http://www.marshallmcluhan.com/main.htmL

47. Véase Javier Plaza-Penades. Cuestiones actuales de Derecho y tecnologías de la información. Revista Aranzadi De Derecho y Nuevas Tecnologías. 2006. 
delicada situación tomó estrategias que permitieran acompasar los alucinantes avances y se preocupó por la normación. Fue así cómo, con la finalidad de universalizar prácticas en torno al ejercicio del comercio globalizado, asumió la búsqueda de la uniformidad, tal como los sostiene Espinosa-Quintero (2004):

La aspiración a un derecho uniforme de los negocios, no es nueva. La búsqueda de la unidad legislativa, jurisprudencial, doctrinal y contractual ha sido una ardua labor de largo aliento, sobre la que, a la fecha, se sigue trabajando en diversos ámbitos. De los primeros pasos hacia una mayor uniformidad, se ha llegado a propuestas más ambiciosas como los «Restatements of law» del «American Law Institute», los «Principios de derecho contractual europeo", el proyecto de UNIDROIT, de principios para los contratos comerciales internacionales, que buscan codificar principios generales en materia contractual, pero con carácter universal. A esto se suma, un amplio elenco de cláusulas standard, condiciones generales, contratos tipo, formularios y demás instrumentos de uniformidad contractual generados a iniciativa de las empresas, asociaciones y corporaciones profesionales. ${ }^{48}$

Así mismo plantea la uniformidad en la contratación y, por ende, en la normación jurídica, permitiendo establecer comportamientos modelo frente a la actividad comercial garantiza qué los principios universales de derecho que se observaron desde los primeros comportamientos del hombre que como actividad natural rigieron en su ejercicio comercial no se perdieran y continuaran vigentes aún en las circunstancias extraordinarias en que hoy nos encontrarnos:

Principios como la buena fe y lealtad negocial (ex fide bona), libertad de contratación y libertad de forma, equilibrio contractual, propios del Derecho Romano, son conciliables con aquellos otros del Common Law como el de «reasonable o reasonably» de uso frecuente en los países anglosajones, como lo refiere el profesor Valiño. ${ }^{49}$

El académico Sánchez, citado en el antes mencionado texto del profesor Espinosa-Quintero, ilustra de manera clara cómo:

48. Véase Leonardo Espinosa Quintero. Hacia un sistema contractual "uniforme": modelos comparados. Civilizar. Enero 2004. Pág. 7. Disponible en: http://repository.usergioarboleda.edu.co/ handle/11232/314

49. Id. Pág. 8 .
Si se quiere un futuro común, se hace necesario mirar retrospectivamente, releer, redescubrir, reencontrarse con el pasado igualmente común, para no quedarse en la búsqueda de un lenguaje jurídico común, sino en la plena integración y armonización jurídica, la cual será progresiva, lenta y blanda (...), no exenta de vicisitudes de variados matices. Basta con referir la que corresponde a la decisión sobre una «codificación regional» o una «codificación global». ${ }^{50}$

Frente a iniciativas como la elaboración de los "Principios de Derecho Contractual Europeo" (Comisión Lando) vs. los Principios unidroit, que acusan diferencias de contenido y suscitan, según el profesor Sánchez, "serias dudas sobre la conveniencia de una codificación regional, que puede resultar contradictoria con una codificación global", ${ }^{51}$ lo que fácilmente concluye la gran dificultad que se enfrenta en el proceso de la unificación.

Los principios de UNIDROIT, según OviedoAlbán, se hicieron con el objetivo de establecer un conjunto de reglas en esta materia, destinadas a ser utilizadas en todo el mundo, independiente de las tradiciones legales y condiciones económico-políticas de los países en donde vayan a ser aplicados.

Los Principios de Unidroit para los contratos comerciales internacionales, conjunto de reglas sugeridas por el Instituto para la Unificación del Derecho Privado con sede en Roma, que representan una aproximación a la unificación y armonización del derecho mercantil internacional y resultan aplicables a los contratos, en principio, por expreso acuerdo entre las partes contratantes. Los principios UNIDROIT contienen conceptos y reglas comunes a varios sistemas jurídicos imperantes en el mundo, de ahí que tal como se explica, laudos internacionales los tomen como ley para los contratos, o como medio para interpretar o complementar instrumentos normativos internacionales, destacándose entre ellos, la Convención de Naciones Unidas sobre Compraventa Internacional de Mercaderías, aprobada por el Congreso por medio de la Ley 518 de $1999 .{ }^{52}$

50. Id. Págs. 6-7

51. Véase Sixto Sánchez-Lorenzo. LA UNIFICACIÓN DEL DERECHO CONTRACTUAL EUROPEO VISTA DESDE EL DERECHO INTERNACIONal privado. aA.vv. Derecho Patrimonial Europeo. Thomson/ Aranzadi. (2003). Citado por Leonardo Espinosa Quintero, supra, nota 48.

52. Véase Jorge Oviedo Albán. Aplicaciones de los principios de UNIDROIT a los contratos comerciales internacionales. CRITERIO JuRíDico 3. 2003. Pág. 7. Disponible en http://revistas.javerianacali. edu.co/index.php/criteriojuridico/article/view/213/924 
Sobre el mismo tema de los intentos de unificación del derecho en materia de obligaciones para facilitar la globalización económica, es pertinente y útil citar a Larroumet:

Los proyectos de unificación son distintos. Así, el texto redactado por la Comisión Lando tiene esencialmente como objetivo las relaciones transfronterizas. Si bien, los redactores consideraron que los principios del derecho europeo de los contratos podrían inspirar a los legisladores nacionales, así como el legislador europeo, es decir la comisión, el consejo y el parlamento, en realidad se trata ante todo de derecho internacional para relaciones transfronterizas.

La inspiración de este sistema de unificación internacional es la de los Principios de UNIDROIT relativos a los contratos del comercio internacional. Tal como los Principios de unidroit, los de la Comisión Lando constituyen una compilación privada sin aprobación de los Estados miembros de la Unión Europea ni de las autoridades europeas. Es cierto que estos principios podrían ser incluidos en un convenio internacional celebrado entre los 25 Estados miembros, pero aún no se ha tratado de hacerlo. La aplicación de los principios del derecho europeo depende hoy, ante todo, de la voluntad de las partes en un contrato, las cuales pueden someterlo a dichos principios. Sin embargo, los principios podrían tener la misma autoridad que la lex mercatoria. La consecuencia sería que, en un pleito internacional, los jueces o los árbitros podrían decidir aplicar estos principios al contrato para resolver el litigio. Es exactamente la solución de los Principios de unidroit. Además, en el mismo sentido podría ser necesario compaginar los principios con una ley nacional aplicable, sobre todo cuando se trata de las reglas imperativas aplicables en materia contractual, independientemente de la ley contractual elegida por las partes en el contrato. En esta aparece que los principios europeos del derecho de los contratos tienen una flexibilidad que resulta muy positiva. Además, respecto al contenido de los principios, no sólo la redacción es clara y constituye un buen compromiso entre sistemas de derecho de tradición distinta, sino que las reglas son más precisas y completas que las de los Principios de unidroit. Por este motivo, no se puede considerar que los principios europeos constituyen una repetición inútil de los Principios de Unidroit. ${ }^{53}$

53. Véase Christian Larroumet. La unificación del derecho de las obligaciones en Europa. Revista de Derecho Privado 13-14. 2006. Págs. 76-77. Disponible en http://www.juridicas.unam.mx/ publica/rev/derpriv/cont/13/dtr/dtr4.htm
Merece entonces especial atención la Comisión Lando, por cuanto es la cristalización de un esfuerzo que se venía haciendo por parte de los estudiosos del derecho, a fin de encontrar la tan anhelada unificación al frente de la cual estuvo el profesor oriundo de Dinamarca Olé Lando, quien con su equipo de trabajo empezó la tarea de unificar los contratos que eran utilizados en la Comunidad Europea, y señaló los principios referidos a tales contrataciones, de modo que constituyó la más completa obra que hoy existe sobre el tema.

La dinámica del texto sugiere en este momento revisar las doctrinas económicas y comerciales desde la principialística, con el propósito de afianzar el evidente cambio de la tendencia que el derecho mercantil ha adquirido hoy en su aplicación. Esto en razón a que estas son el reflejo de las tendencias que el ser humano adopta frente a la solución de las necesidades con sus problemas y, con relación a las doctrinas económicas, se supone que la evolución en el campo comercial, es decir, en el comportamiento de las relaciones mercantiles del hombre, la evolución tiene que responder a unos avances lógicos y jurídicos que permitan mantener la convivencia, máxime hoy cuando la tendencia es globalizada.

\section{TEORIZACIÓN SOBRE}

\section{LOS TIPOS DE ESTADO}

El derecho mercantil, como conducta humana producto de la convivencia en sociedad, es un comportamiento que debe ser regulado de acuerdo con las situaciones particulares, los usos y las costumbres de cada asociación humana - de cada Estado-. Por tanto, es necesario revisar las teorías del Estado con el fin de desentrañar de qué manera considera tal postura la cuestión de la conducta mercantil. Cada Estado posee una organización, la cual es producto de un liderazgo de identificaciones de orden humano que, con razones o sin ellas, han escogido una doctrina para aplicarla en su organización estatal. Estas no serán iguales y, por lo tanto, habrá Estados que tienen un sistema en el derecho comercial diferente a otros. La implicación directa de todo lo anterior es la creación de sistemas jurídicos independientes, cada uno en busca de la mejor aplicación de lo que esa comunidad piensa que es lo óptimo para el ejercicio del derecho comercial. Todo esto se convierte en un obstáculo para la uniformidad en el derecho mercantil, así como de los principios que son el 
ejercicio que surge como respuesta a la tendencia de la globalización.

\section{A. Estado liberal}

En la concepción liberal, el Estado es el servidor de la sociedad. Así lo concibe Locke ${ }^{54}$ al establecer que, por consiguiente, el grande y principal fin que lleva a los hombres a unirse en Estados y a ponerse bajo un gobierno, es la preservación de su propiedad. Para lo cual el Estado debe proveer al hombre de leyes fijas, conocidas y aceptadas por consentimiento; un juez público e imparcial, con autoridad para resolver los pleitos entre los hombres; $y$, por último, instituir un poder que respalde la fuerza de tales sentencias cuando estas sean justas. Así, todo gobernante tiene el compromiso de velar mediante unas leyes adecuadas, encaminadas a la protección de esa propiedad, a fin de que el individuo pueda desarrollarse libremente y así evitar que, al hacerlo, entre en conflicto con el uso de la libertad de los demás.

La tendencia que se genera para el derecho mercantil y lo relacionado con el factor económico dentro de esta teoría, consiste en una total permisividad de la gestión, del comportamiento del intercambio de bienes y servicios, motivo por el cual la norma, escasa por cierto, lo único que pretende es establecer de manera incipiente cuáles serían los campos en los que el ser humano, el asociado al Estado, podría adelantar tal acción sin detenerse a regularlo, a orientarlo para precaver los conflictos. Ya se mencionaron las lamentables consecuencias ${ }^{55}$ que acarreó esta actividad contemplativa por parte del Estado frente a una circunstancia tan delicada como lo es la actividad mercantil; por el contrario, el Estado de derecho, sí la regula y dejó la organización de todo un sistema codificado que apartó estos comportamientos de la rama del derecho civil, de modo que conformó una

54. Locke considera que el derecho más difícil que se da en el estado de naturaleza es el de propiedad. Para defender estos derechos surge la sociedad, el derecho y la autoridad. La sociedad, por medio de su ordenamiento jurídico, tiene su razón de ser en el garantizar la vida, la libertad y la propiedad de los individuos. La sociedad nace del consentimiento (contrato social) de los individuos que buscan proteger sus derechos naturales a la vida, a la libertad y a la propiedad. Pero el poder político, que los individuos ceden al Estado cuando este nace, puede siempre ser reasumido por ellos. El Estado no tiene otro fin que el de velar por los individuos, por su bienestar y su propiedad, la cual no tiene derecho a enajenar. Y para amparar al individuo de una potencial exacerbación del poder estatal, Locke propugna la división equilibrada del poder político en legislativo y ejecutivo.

55. Este acápite se refiere a la profundización de las desigualdades sociales. nueva que es el derecho comercial. Esto constituyó un avance, pero conllevó una problemática: la que surge a partir de la insipiencia de los asociados en la actividad comercial, quienes pasaron de la noche a la mañana de tener una actividad totalmente liberal, a tener un ejercicio totalmente contralado, lo cual se miró como el fuerte intervencionismo en la economía.

\section{B. Estado de derecho}

Conocido en francés como "Etat de Droit"; en el alemán como "Rechtstaat"; y en inglés como "legal State" o "rule of law", se nomina a esta forma lo que en el contexto hispanohablante se denomina como "Estado de derecho". Sin embargo, a pesar de la variedad en el lenguaje, se guarda una identidad en su significado, toda vez que la idea contenida lleva a conocerlo como un concepto por medio del cual las sociedades organizadas se oponen al modelo de Estado propuesto o, mejor, surgido con motivo de la Revolución francesa, caracterizado con la célebre expresión "lesse fer, lesse passer", propio del "Estado gendarme". Surge, pues, este modelo de Estado que se apega, por esencia, al "derecho", pero bajo unas condiciones inamovibles: (a) el imperio de la ley, (b) separación de los poderes, (c) legalidad de la administración, y (d) distribución del poder estatal en órganos y no en funcionarios.

El Estado de derecho tiene entonces un reconocimiento teórico basado en unas características que lo distinguen clara y precisamente de otros tipos teóricos de Estado, tales como la creación de organismos de poder con autonomía para sus actuaciones, los cuales deben ser institucionalizados, y no darse en forma de personas; el nombramiento de los funcionarios según la norma; y, sobre todo, el respeto de los derechos inherentes al ser humano. Es decir, se trata del imperio del derecho mediante la taxativa aplicación de la norma. ${ }^{56}$

\section{Estado social de derecho}

Celso Nogales, en la elaboración de su marco teórico, al respecto refiere que la razón de ser de esta nueva concepción organizativa de un Estado posiblemente surge de reconsiderar el papel del individuo asociado frente al Estado que lo organiza. Ya no se trataba de la preocupación por encontrar justificación a la razón

\footnotetext{
56. Cf. Celso Nogales-Rodríguez. Marco Teórico. Proyecto De INVESTIGACIÓN CONCEPTO Y FUNDAMENTO DE LA VIVIENDA EN Colombia.
} 
por la cual un Estado debía ser un ente superior al individuo mediante poder y autoridad para lograr su ordenamiento en la sociedad, si no que se trata de hacer valer a ese ser humano frente a la majestad del Estado. Con el Estado de Derecho, era la norma la que, como un mecanismo, permitía el reconocimiento y defensa del derecho humano, pero esta elaboración que el legislador hacía de la misma tomaba al hombre como un "conejillo de pruebas" a quien con posterioridad de la validez de tales disposiciones se convertía en víctima de la misma. Para sofocar esa incómoda postura y a la postre injusta con el hombre mismo, al concepto estado de derecho se le adicionó un calificativo: el de social. Se trata, entonces, de un Estado al que la norma lo rige, pero que, para obtener como resultado la ley, se parte incuestionablemente de factores humanos como son la dignidad, el respeto a la convivencia, la realidad de las necesidades humanas, etc.; todo lo cual da un tinte más humano a la norma fría, al artículo ajeno a la circunstancia evidente de lo que el hombre es frente a su existencia en una nación. Una mirada al hombre bajo la óptica del Estado Social de Derecho impone no solamente hacerlo desde el contexto legal, sino desde el ámbito natural; esto es, que el ser humano, además de necesidades materiales provenientes del ejercicio de su existencia, también las tiene de tipo emocional, cultural, espiritual, ideológico, etc., que, no por abstractas, tienen menor valor que las primeras, pudiendo acuñar con todo esto el denominado principio de la "seguridad humana", que estaba contemplado por los antiguos a través de los denominados brocardos universales de derecho, es decir, lo que el profesor Valencia sostiene que, al perfilar el concepto de las reglas de derecho, contribuyó también en amplia medida a la distinción establecida por glosadores y comentaristas de los textos jurídico-romanos canónicos y recogida luego por los tratadistas de la materia de los siglos XVI, XVII Y XVIII, diferenciando las auténticas o legales, de las doctrinales o brocardos, del mismo modo que se distinguía, entre las compilaciones jurídicas medievales, las auténticas u oficiales, sancionadas como tales por el legislador de las que, carentes de autoridad legal, eran debidas a la iniciativa privada. ${ }^{57}$

Al realizar un bosquejo genérico, se puede afirmar que la idea de lo humano invade el concepto de Estado social de derecho, mientras la noción hombre lo hace frente al Estado de derecho. Tal afirmación se encuentra respalda en múltiples argumentos

57. Véase Hernán Valencia-Restrepo, supra, nota 2. extractados del inteligenciamiento que sobre el tenor filosófico insinúa el concepto, lo que implica, por ejemplo, discurrir sobre la dimensión del hombre, no como ser biológico, sino como ser humano, ya que mientras en el primer supuesto el individuo como ente natural contempla unas exigencias, esto es, unas necesidades provenientes específicamente en orden a su materialidad, en la segunda contemplación, el hombre, como ser humano, conlleva una complejidad, dada la abstracción multifactorial de los elementos que la integran. Así, por ejemplo, no solo debe atenderse al hombre en su necesidad funcional biológica (nacer, crecer, reproducirse y morir), sino que tales exigencias materiales, implícitamente, conlleven una trascendencia que se evidencia en la calidad del nacimiento. El derecho debe preocuparse porque toda persona nazca en condiciones dignas, pues no es posible que el Estado desatienda a personas menos favorecidas con el fin de adelantar el ejercicio de tan elemental necesidad como es el nacimiento y, más allá, debe protegerse la gestación como el principio fundamental que anima el resultado de un ser que tiene las condiciones para enfrentar una verdadera existencia. Asimismo, debe evidenciarse el crecimiento del ser humano bajo circunstancias que correspondan a su condición de ser racional, proporcionándosele los medios para su estructuración física, mental y social, e igual debe suceder con la reproducción y la muerte de este ser por excelencia. Baste este análisis para evidenciar la diferencia objetiva entre el hombre como concepto biológico, y el hombre como concepto humano

\section{ConCLUSIONES}

Una teoría o doctrina económica es una sistematización de principios o leyes económicas, por medio de la cual se analizan la realidad y los fenómenos económicos que en ella ocurren, de forma integral. Aquellas que explican la realidad parcialmente no constituyen doctrinas, sino solo pensamientos económicos. Una característica fundamental de las doctrinas económicas es que no surgen de la nada. Aparecen por la observación de la realidad, es decir, responden a un contexto social determinado.

De acuerdo con La Constitución de 1991:

Colombia es un Estado social de derecho, organizado en forma de república unitaria, descentralizada, con autonomía de sus entidades territoriales, democrática, participativa y pluralista, fundada en el respeto de 
la dignidad humana, en el trabajo y la solidaridad de las personas que la integran y en la prevalencia del interés general. ${ }^{58}$

Así, el Estado debe entenderse como el agrupamiento social en un territorio determinado y reconocido, constituido bajo la legitimidad de un poder político público que abarque normas respaldadas jurídicamente, en el propósito de mantener un orden social.

El Estado se puede entender como una organización de la sociedad, con elementos que hacen que no solo el gobierno y las autoridades manejen y controlen el poder - como en muchos casos se cree-, sino que, por el contrario, se establezcan parámetros y normas a fin de que se logre establecer una convivencia armónica entre la libertad y el poder. La función judicial, que es la encargada de manejar el derecho, es decir, se encarga de juzgar y, por medio de las leyes que se establezcan dentro de la constitución del Estado, buscar una solución a los conflictos que se presenten entre individuos o entre particulares y el Estado

El estudio y el desarrollo de la ciencia jurídica, debido a las complicaciones que se presentan a lo largo de la historia y, especialmente, de la sociedad moderna, ha exigido, tanto al Estado, como a los que hacen parte del sistema jurídico, numerables formas y métodos de cómo hacer que la justicia sea más rápida y efectiva. Esta búsqueda de salidas y variaciones en la norma ha generado un gran impacto social, en la medida en que no solo el Estado ha asumido la responsabilidad de mejorar la justicia, sino que cada individuo se ha hecho parte de esta gran tarea. Los principios no solo dependerán de la norma creada, sino fundamentalmente de la actitud enérgica y laboriosa de las partes que construyen un proceso, las cuales deben buscar siempre una justicia más humana.

El hombre, desde los inicios de la historia de la humanidad, ha estado acompañado de una necesidad permanente de tener bienes y servicios que satisfagan sus necesidades, así no tuviera la conciencia de una actividad mercantil. Es allí donde se encuentra la génesis de los principios que enrutaron el comportamiento mercantilista que a través del tiempo ha ido evolucionando $y$, dada su importancia, el hombre positivizó mediante unas normas que van desde un Estado caracterizado por su aplicación fría, hasta el Estado moderno en el que hay una alimentación

58. Véase Constitución Política de Colombia [Const]. De los Principios Fundamentales, Artículo 1 y 2. Julio 7 de 1991 (Colombia) práctica de la función social que debe cumplir la norma en el Estado.

Administrar justicia, legislar y ejecutar desde un Estado de derecho, no es lo mismo a hacerlo desde un Estado social de derecho, pues los principios tornan su objetivo hacia el fenómeno de ente comunitario, y no de normas. Mirado así, el ámbito de lo mercantil tiene que ser impactado con la tendencia anunciada, pues de no serlo se tornaría un elemento excluido del contexto que se propone tan novedosa figura.

\section{REFERENCIAS}

Alfredo Cogorno. Elementos del seguro. Herrera - DKP. Disponible en http://www.hdkp.pe/sp/informacion/ elementos_del_seguro.html

Arte historia. Conquista de la Galia Cisalpina. Disponible en https:/www.artehistoria.com/es/contexto/ conquista-de-la-galia-cisalpina

Celso Nogales-Rodríguez. Marco Teórico. Proyecto DE INVESTIGACión CONCEPTO Y FUNDAMENTO DE LA VIVIENDA EN COLOMBIA. Disponible en https://issuu. com/editorial_usc/docs/taco.1

Carlos López Rodríguez. El Derecho Comercial en la Edad Media. Disponible en http://www.derechocomercial.edu.uy/RespDerechoComEdadMedia.htm

Christian Larroumet. La unificación del derecho de las obligaciones en Europa. Revista de Derecho Privado 13-14. 2006. Págs. 69-80. Disponible en http://www. juridicas.unam.mx/publica/rev/derpriv/cont/13/dtr/ dtr4.htm

Claudia Helena Forero Forero. Principios constitucionales: manifestación positiva de los principios generales del derecho (sistema jurídico colombiano: derecho en parte natural y en parte positivo). Revista TelemáticA DE Filosofía del Derecho 6. 2002/2003. Pág.167-192. Disponible en http://www.rtfd.es/numero6/10-6.pdf.

Constitución Política de Colombia [Const]. De los Principios Fundamentales, Artículo 1 y 2. Julio 7 de 1991 (Colombia).

Corte Constitucional Colombiana. Sentencia C-479 de 1992. (MP José Gregorio Hernández y Alejandro Martínez Caballero: Agosto 13 de 1992).

Corte Constitucional Colombiana. Sentencia T-531/92. (MP Eduardo Cifuentes Muñoz: Septiembre 23 de 1992).

Corte Constitucional Colombiana. Sentencia T-516/92. (MP Simón Rodríguez-Rodriguez, Fabio Moron, Jaime Sanin: Septiembre 15 de 1992). 
Corte Constitucional Colombiana. Sentencia T-533/92. (MP Eduardo Cifuentes Muñoz: Septiembre 23 de 1992).

Corte Constitucional Colombiana. Sentencia C-543/92. (MP José Gregorio Hernández: Octubre 1 de 1992).

Corte Constitucional Colombiana. Sentencia C-574/92. (MP Ciro Angarita Barón: Octubre 28 de 1992).

Corte Constitucional Colombiana. Sentencia C-599/92. (MP Fabio Morón Díaz: Diciembre 10 de 1992).

Corte Constitucional Colombiana. Sentencia T-614/92. (MP José Gregorio Hernández: Diciembre 15 de 1992).

Corte Constitucional Colombiana. Sentencia T-011/93. (MP Alejandro Martínez Caballero: Enero 18 de 1993).

Corte Constitucional Colombiana. SENTENCIA C-019. (MP Ciro Angarita: Enero 25 de 1993).

Corte Constitucional Colombiana. Sentencia C-112/93. (MP Hernando Herrera Vergara: Marzo 25 de 1993).

Corte Constitucional Colombiana. Sentencia C-486/93. (MP Eduardo Cifuentes Muñoz: Octubre 28 de 1993).

Corte Constitucional Colombiana. Sentencia T-097/94. (MP Eduardo Cifuentes Muñoz: Marzo 7 de 1994).

Corte Constitucional Colombiana. Sentencia T-296/94. (mp Carlos Gaviria Díaz: Junio 29 de 1994).

Corte Constitucional Colombiana. Sentencia C-225/95. (MP Alejandro Martínez Caballero: Mayo 18 de 1995).

Corte Constitución Colombiana. Sentencia C-280/96 Fundamento 3. (MP Alejandro Martínez Caballero: Junio 25 de 1996).

Frida Gisela Ortiz-Uribe y María del Pilar García. MetoDOLOGÍA DE LA INVESTIGACIÓN: EL PROCESO Y SUS TÉCNICAS. Limusa. (2003).

Gabriel Tortella. LA Revolución DEL SIgLO Xx. Taurus. (2000).

Gerencie.com. Principio de Estado Social de derecho. Disponible en http://www.gerencie.com/principiode-estado-social-de-derecho.html

Hernán Valencia-Restrepo. Conferencia dos DefinicioNES DE LOS PRINCIPIOS GENERALES DEL DERECHO. Editorial Temis. $3^{\text {a }}$ edición. (2005).

Hernán Valencia-Restrepo. NomoÁrQUICA, PRINCIPIALÍsTICA JURÍDICA O LOS PRINCIPIOS GENERALES DEL DERECHO. Bogotá: Editorial Temis. (1993).

Javier Plaza-Penades. Cuestiones actuales de Derecho y tecnologías de la información. Revista Aranzadi DE DereCho y Nuevas Tecnologías. 2006.
Jorge Oviedo Albán. Aplicaciones de los principios de UNIDROIT a los contratos comerciales internacionales. Criterio Jurídico 3. 2003. Pág. 7-33. Disponible en http://revistas.javerianacali.edu.co/index.php/criteriojuridico/article/view/213/924

Juan de Pablos Pons. Las TeCNOlOGías de LA INFORMACión Y LA COMUNICACIÓN: UN PUNTO DE VISTA EDUCATIvo. Disponible en https://webs.ucm.es/info/multidoc/ multidoc/revista/num8/jpablos.html

Leonardo Espinosa Quintero. Hacia un sistema contractual "uniforme": modelos comparados. Civilizar. Enero 2004. Disponible en: http://repository.usergioarboleda.edu.co/handle/11232/314

Lizandro Alfonso Cabrera Suárez. Los principios y su papel en la crisis de las fuentes del derecho. CRITERIO LIBRE JURÍDICO 8(1). (Enero-Junio 2011).

Manuel S. Saavedra. ElABORACIÓN DE TESIS PROFESIONALES. (2001).

Marco Monrroy-Cabra. Anuario Constitucional CoLOMBIANO. (2001).

Martí Batres Guadarrama. Estado de derecho. LA JoRNADA. Disponible en http://www.jornada.unam. $\mathrm{mx} / 2005 / 04 / 21 /$ index.php? section $=$ politica \&arti cle $=023 \mathrm{a} 2 \mathrm{pol}$

Miguel Ángel Vásquez-Ruiz. Economía y Sociedad, Documentos de Trabajo Número 3. Agosto de 1997.

Norberto Bobbio. TeOría General DEL DERECHO. Editorial Temis. (1987).

Octavio Lanni. Teorías DE LA GLObalización. Siglo XXI. (1996).

Pablo Raul Bonorino. InTEgridad, DERECHO Y JUsticia. UNA CRÍTICA A LA TEORÍA DE RONALD DWORKIN. Universidad Nacional de Colombia. (2003).

Paola Andrea Ramírez. Iusnaturalismo. 25 de septiembre de 2009. Disponible en http://teoriadelderecho14. blogspot.com/2009/09/iusnaturalismo.html

Real Academia Española. Globalización. DLE.RAE.ES.

Rene Cadena-Afanador. Impacto en Colombia de la Lex Mercatoria. Revista Civilizar 11. Disponible en http:// www.redalyc.org/pdf/1002/100220305013.pdf

Tomás Austin. Guía N. ${ }^{\circ}$ 3. MARCo TEÓRICO. Disponible en http://www.angelfire.com/ emo/tomaustin/ Met/guiatresmarco.HTM

Walter René Cadena-Afanador. Impacto en Colombia de la Lex Mercatoria. Revista Civilizar 7(12). 2007. Págs. 1-21. Disponible en http://www.redalyc.org/ pdf/1002/100220305013.pdf 